\title{
Scratching the Surface: Exploring Women's Roles in Artisanal and Small Scale Mining in Zimbabwe
}

\author{
Munyaradzi A. Dzvimbo ${ }^{1}$, Colleen Ncube ${ }^{2}$, Monica Monga ${ }^{3}$ \\ 1, 2, ${ }^{3}$ Department of Development Studies, Lupane State University, Zimbabwe \\ munyadzvimbo@gmail.com
}

\begin{abstract}
Artisanal mining communities around the world are diverse, dynamic and distinct in nature they vary from culture-to-culture, region-to-region and mine-to-mine, and change over the course of time.Women within these communities are also heterogeneous and unique; however, they tend to be engaged in specific roles throughout the world.A qualitative approach in form of a descriptive survey research design was adopted, in which purposive systematic sampling was used and qualitative data was generated. Semi-structured questionnaires were used to collect data from predominantly mining towns Kadoma, Kwekwe and Shurugwi as well surrounding areas.The sample size was compelled by the different mining areas which are a considerable distance from each other with sparsely distributed population. The focus of data collection was on women's responsibilities in mineral processing activities range from crushing, grinding, sieving, washing and panning, to amalgamation and amalgam decomposition in the case of gold mining.Typically, women are labourers (e.g. panners, ore carriers and processors), providers of goods and services (for instance cooks, shopkeepers) and are often solely responsible for domestic chores. The total number of artisanal miners for the three mining towns was 1500 and a sample of $10 \%$ (150 miners) of the three towns, with each town having 50 was sampled. The artisanal miners taken to be part of the population sample were systematic selected till the last person. The composition of the miners was made up $41 \%$ of the females while the remaining $59 \%$ were male respondents.
\end{abstract}

Keywords : artisanal; entrepreneurship; gender; mining women

\section{Introduction}

Artisanal mining communities around the worldare diverse, dynamic and distinct in nature they varyfrom culture-to-culture, region-to-region andmine-to-mine, and change over the course oftime. Women within these communities arealso heterogeneous and unique; however, theytend to be engaged in specific roles throughoutthe world (Keck, 2006). Typically, they are labourers (e.g.panners, ore carriers and processors), providers of goods and services (for instancecooks, shopkeepers)and are often solely responsible for domesticchores. Women's responsibilities in mineralprocessing activities range from crushing,grinding, sieving, washing and panning, toamalgamation and amalgam decomposition in the case of gold mining (Fourie, 2009). Less commonly, women are concession owners, mine operators, dealers and buying agents, and equipment owners. In many locales, women function in multiple capacities. For instance, a woman working as a panner may also obtain income as a sex trade worker and a cook. Despite the diverse and important roles undertaken by women in artisanal mining, limited reliable information is available on this topic. The numbers of women involved have been estimated in several countries; however, there are very few accounts telling the stories of individual women and a paucity of information concerning the age, ethnicity, status, wealth, and health of both women and men in these communities.

In countries like Kenya and Tanzania alluvial miners contribute up to $25 \%$ of the total production. Nivak and Mishra (2002) assert that more than 50\% that are actively involved in alluvial gold mining are women and children. In Zimbabwe, 1.3 million women in the rural areas are involved in mining (UNDP, 2014). UNIFEM (2002) further goes on to say that an 
estimated $70 \%$ of the world's 1.3 billion poor are comprised of women and girls. The feminization of poverty combined with other factors for example cultural norms with respect to gender roles and lack of employment in other sectors and high fertility rates, have led to the escalation of women's direct and indirect involvement in livelihoods improvement.

Mining is not a new phenomenon in Zimbabwe nor was it introduced during colonization. Since time immemorial, both men and women have been engaged in various mining activities in order to meet their human essential needs, such as manufacture of tools and implements to use in agriculture and hunting, shelter, weapons, ornaments, structures, transport devices and machinery (UNIFEM 1999). Mining projects are often established on land which is already occupied and used by people who depend on farming, livestock rearing and fishing for their livelihoods.Given this backdrop the study seeks to assess the role of women in artisanal mining and reflect on the challenges they face in the mining processes.

\subsection{Problem Statement}

Women face different economic challenges as a result of the lack of access to, use of and control over resourceful land and other productive resources, licences, finance, and geological data. In many cases, such as that observed in Zimbabwe, traditional beliefs prevent women from these utilizing these economic factors, denying them any control over earnings. The inability to access finance contributes to women's inability to invest in mining equipment and technology necessary for a successful business (Nel, 2012). At policy level, the existing discrimination against women often puts them at a lower order in policy decisions affecting them. The de jure and de facto inequity in access to and control over land and property rights constrains women from accessing various other determinants of mining business success, such as finance.

Due to the traditionally influenced legal constraints to owning or inheriting land and mineral rights, many women end up operating unregistered. This increases their vulnerability in the current global efforts to promote formalization, which, in itself, is characterized by arduous requirements many women are unable to fulfill. Without a commitment to gender mainstreaming, existing prejudices can be reinforced by the formalization process stifling women's capacity to contribute to a productive and responsible mining sector. Strong cultural norms have influenced legal approaches to gender issues resulting in subtle and, at times, open legal discriminations against women (Guild, 2008). Thus, legal and cultural discriminations, domestic and childcare responsibilities, and lack of education have relegated women to passive participation, making it difficult for women to openly air their concerns and ideas in front of men.

This lower status has meant women have little to no power or influence in actively participating in key decision-making processes. As a result, women's views, needs, ideas and potential to contribute to solutions are overlooked. Women's groups which could represent women's interests in most cases get off to a good start, only to struggle due to lack of organizational structure and institutional capacity, competition for power, weak leadership and corruption.

\subsection{Objectives of the study}

$>$ To establish the women's roles in artisanal and small scale mining in Zimbabwe.

$>$ To investigate the opportunities and challenges faced by womenartisanal and small scale mining in Zimbabwe. 


\section{Literature Review}

It is rare to see women involved in the actual digging of ores, essentially barred from any activity that involves first contact (mineral discovery) and last contact (sale of minerals). While this may be associated with the lack of access to land and mineral resources, women is generally still not seen digging or operating equipment in pit areas even if they own land or mining licences. This is often attributed to the cultural barriers that prohibit women from physically demanding activities, which are usually deemed to be "men's work." The masculine image of "the miner" created in early industrial days when mining was a dangerous, laborious and risky operation continues to have a strong effect excluding women from heavy mining duties (Lahiri-Dutt, 2012). Cultural barriers also amount to taboos due to the belief that female miners are "loose women," and they are deemed unclean, excluding them from carrying out underground mining (Verbrugge, 2017). These barriers manifest in many countries with a connotation that women cause a "spirit" of bad luck when in close proximity to minerals or mineral-bearing stones; hence the justification for banning them from pits (Hinton et al., 2003). They also restrict women's access to the valuable first pickings.

"The miner" that carries out heavy mining duties in pits tends to receive most of the publicity, whereas women's participation in activities outside pits gets ignored and undocumented, although they contribute to a significant part of the mining operation (Bilton, 2002). In order to fully account for women's roles and understand the opportunities for their greater participation, therefore, the phrases "women as miners" and "women in ASM" should encompass the whole cycle of mining and related activities from exploration to consumption. Indeed, those who are not part of the traditional "miner" workforce but perform all other activities except digging (may be referred to as "extended miners") need to be recognized. By and large, a woman's potential for successful entrepreneurship in ASM lies within the whole spectrum of activities including mining, processing, delivery, and goods and service provision in and around ASM.

Women of all ages are seen in mineral and quarry rush areas either individually, with partners and/or children carrying out minor digging, shoveling and collecting mineral-bearing ores and quarry materials. While they are involved in significant numbers and for extended periods, the likelihood of succeeding in discovery and thus benefiting from sales is minimal. Even if they succeed in mineral and quarry discovery, the prices at which they sell their unprocessed finds is far lower than the actual value (Grobler, 2011). This can be due to a lack of information and awareness about mineral and quarry material values and market prices which compel women to deal with on-site buyers.

The number of women involved in what is commonly known as auxiliary roles performing all activities except heavy mining duties in pit areas is significant; in Tanzania for example, the number is estimated to be about 2.5 times those working in direct mineral production (Eftimie et al., 2012). However, performing these roles does not usually translate in women benefiting, as in many cases women are either underpaid, exploited or deprived of information on any financial flow due to culturally and violently imposed control by men. For example, women engaged in processing and hauling roles in Ghana earn 60 per cent less than men in digging roles; 80 per cent of profit from washing gold from lateritic soil carried out by women in Guinea goes to male intermediary buyers (Eftimie et al., 2012). Therefore, while their involvement in the various non-digging activities in ASM presents an opportunity to maximize their potential, these and other barriers need to be addressed. 
Due to the low remuneration and other gendered disadvantages, many women (including those that migrated to ASM areas to make a living from working in mining activities or in the bars and hotels of mining towns) end up engaging in sex activities (Verbrugge, 2017). Some women enter the sex business as a bargaining tool to access and maintain employment and are prone to serious health risks (including sexually transmitted diseases) while being susceptible to social exclusion and sexual and physical abuse (Kelly, King-Close, \& Perks, 2014). Many young women choose not to return to their homes for fear of stigmatization, leaving them vulnerable. The lack of formal recognition of sex services becomes an issue for any potential intervention to address these health risks or see whether women can leverage some economic advantages out of their involvement in such services.

In addition to financial exploitation, women are exposed to health risks such as brain, kidney and lung damage, particularly because it is women who often perform ore purification using mercury or cyanide and scavenge tailings where they encounter with chemicals such as cyanide (Eftimie et al., 2009). Women are further prone to health issues such as lung diseases, skin irritation and eye damage through dust from ore crashing; and musculoskeletal disorders from manual lifting and carrying of materials and awkward positioning (Lu, 2012). Women also suffer from fatigue due to the physical demands not only of performing the aforementioned activities but also the domestic responsibilities they are traditionally charged with, such as childcare, food and drink preparation, and cleaning among others. The cultural constraints go deeper, in that women in some cases find themselves at the bottom of the family order when it comes to rest, comfort and nutrition in homes leading to their increased vulnerability to health risks (Chakravorty, 2001).

Domestic responsibilities also affect women by limiting the amount of time and effort they can spend in mining sites, thus missing any financial, networking and mining knowledge gains. Therefore, time and mobility (two factors highlighted by Oduro and Van Staveren, 2015) are taken away from women, preventing them from making any meaningful progress in financial gains or entrepreneurial aspirations. For example, the time and resources required to obtain mining permits from offices far from home are beyond many entrepreneurial women burdened with domestic work. This unrecognized, unequal and highly burdensome work makes it difficult for women to advance past subsistence activities, as they lack the time and mobility to take part in dialogue, training and to undertake even small administrative tasks that would help recognition of their activities.

The organization of female labour in ASM differs across countries in the global south, which can be attributed to differences in mineral ores, mining equipment and technology, cultural and gender taboos, and political factors. In most cases, however, the sexual division of labour that exists in ASM areas often manifests in the way ASM groups or cooperatives are formed. ASM cooperatives often follow hierarchical systems or top-down organization, with a licence owner at the top followed by pit holder and then mine workers (diggers) (Jønsson \& Bryceson, 2009). This categorically disqualifies women from even being part of cooperatives, given they are rarely licence holders, pit owners or diggers. Such deprivations are also behind women's inability to form strong women-only cooperatives. In Tanzania, for example, mining is an individual affair for women, although some women do form partnerships with family members (e.g., mother and children, husband and wife, particularly during the rainy season) or forge temporary alliances with other miners to achieve a common goal (e.g., money for a wedding) (Verbrugge, 2017). Many women also form rotating savings and credit associations to boost their income from mining, but often the cooperation between female miners does not 
extend beyond these boundaries. This worrying trend away from cooperative participation that is typically seen in women in ASM may deteriorate their participation in mining, as many governments and international organizations increasingly encourage cooperative organizations.

Among the reasons for the limited participation of women in ASM groupings or cooperatives is the lack of trust that exists, especially as ASM often involves migration-many women fear the consequences of failed reciprocity in working relationships. Domestic and childcare responsibilities also make it hard for some women to have (and stick with) the allocated commitment toward group activities. This is because domestic responsibilities vary in terms of extent and timing across households. Furthermore, as with other aspects, women are subject to unfavourable (or nonexistent) government policies needed to support the establishment of artisanal mining groups and cooperatives. Although promoting ASM cooperatives is taken as part of formalization strategies, governments have generally put more focus on licensing to generate revenue, rather than empowering miners through the establishment of cooperatives (Maconachie \& Hilson, 2011b). In countries that have witnessed an increase in mining cooperatives such as the Democratic Republic of the Congo, the results show corrupt governance with elites wielding power and exploiting miners (De Haan \& Geenen, 2016).

\subsection{Theoretical Review}

The Sustainable Livelihood Framework was used as a tool to analyze livelihoods and poverty reduction. The framework states that vulnerability context characterized by shocks; seasonality and national economic trends have an influence on rural projects and programmes. The context which a project is in can affect either positively or negatively asset utilization. Assets can be used to avert unfavorable conditions but institutions, processes and organizational structure would have created an atmosphere conducive to efficient and effective utilization of assets. Institutions and organizations deter or facilitate livelihood strategies (Bade, 2000). The theory enables vulnerable communities to access to assets. Institutions and organizations are transforming processes; hence, can deliver or negatively affect sustainability in rural livelihoods (Scoones, 2010).

According to Robert Chambers and Gordon Conway (1992), among the variety of components of a livelihood, the most complex is the portfolio of assets, which includes both tangible assets (resources) and intangible assets such as claims and access out of which people build their living. They also stressed that, any sustainable livelihood approach has to include the ability to cope or avoid or recover from stresses and shocks (Benya, 2009).

Similarly Carney (2012:4) and DFID (2009:5) define Livelihood approach as encompassing;

"The capabilities and assets (material and social) resources and activities required for a means of living. A livelihood is considered to be sustainable when it can cope with and recover from stress and shocks and maintain or enhance its capabilities and assets both now and in the future without undermining the natural resource base".

\section{Methodology}

A qualitative approach in the form of a descriptive survey research design was adopted, inwhich purposive systematic sampling was used and qualitative data was generated. Semistructuredquestionnaires were used to collect data from predominantly mining townsof 
Kadoma, Kwekwe and Shurugwi as well surrounding areas. The sample size was compelled by the different mining areas which are a considerable distance from each other with sparsely distributed population. The focus of data collection was on women's responsibilities in mineral processing activities ranging from crushing, grinding, sieving, washing and panning, to amalgamation and amalgam decomposition in the case of gold mining (Fourie, 2009). Typically, women are labourers (e.g. panners, ore carriers and processors), providers of goods and services (for instance cooks, shopkeepers) and are often solely responsible for domestic chores. The total number of artisanal miners for the three mining towns was 1500 and a sample of $10 \%$ (150miners) of the three towns, with each town having 50 was sampled.The artisanal miners taken to be part of the population samplesystematically selected till the last person. The composition of the miners was made up $41 \%$ of the females while the remaining $59 \%$ were malerespondents.

\section{Discussion of Results}

\subsection{Socio-economic benefits and Livelihoods}

The study noted that local economic progress is inconsequential with $56 \%$ of the respondents showing that gold mining proceeds has insignificantly improved infrastructure and community development such as roads networks, educational institutions and social services providers such as hospitals and clinics. A total of $44 \%$ of respondents showed that mining entities have at least rehabilitated a school or serviced road network as part of the Corporate Social Responsibility (CSR)programme. Mining companies such as Ronghi Xi have actually been bringing their own citizens from China while failing to employ local people in secure and well-paying jobs. According to Fourie (2009) employment of local residents in the mining sector have improved their financial status and social standing,thus lack of jobs have compromised economic development.It is however vital to point out that $88 \%$ of the respondents indicated that they were not reaping benefits but cross-scale exclusiveseizure by investors, government and traditional leaders and well-connected individuals occurs. However all this was necessitated by lack of any progress and meaningful infrastructural development and related investments coming into the community to create jobs and improve local livelihoods.

\subsection{Unavailability of Basic Services}

The Midlands province, which lies in the central part of Zimbabwe,is a vast rural and urban area which faces a number of problems emanating from poor basic services provision. In Shurugwi district there has been no water reticulation system hence no piped water and proper solid waste disposal systems (Perks, 2014). The provision of water is important for survival and for a healthy life. UNDP (2011) opines that access to adequate and clean water for consumption is essential to obtain a healthy life while appropriate sanitation averts diseases while in the process assuringdignity to mankind. In the three areas where this study was carried out, Shurugwi, Kwekwe and Kadoma, water sources such as boreholes and rivers had contaminated water mainly as a result of the chemicals which were being used in their mining activities. Sixty one per cent $(61 \%)$ of the people have no access to clean fresh water and get drinking water from shallow wells, pits and streams. Thirty-nine per cent (39\%) of respondents have access to clean water obtained from boreholes and protected wells provided by government, mines or NGOs. However, the water is considered unsafe by some as it is rusty 
and causes stomach ailments. Clean water access is also a challenge for the surrounding schools as well due to unrepaired boreholes.

\subsection{Employment opportunities for the local people}

The study has revealed that fewer job opportunities for locals who have become dependent on illegal mining activities exist while mining companies recruiting labour from neighbouring towns. Many of the jobs are of casual in nature as well as short-term contracts. A sad development which has been noted through this study has been the gross violation of labour laws by these mining companies. They hire and fire people on short contracts without any compensation. This has resulted in most of the affected people having their livelihoods affected. However, employment in the mining sector in Shurugwi district isalso gendered with fewer than $15 \%$ of workers being women and employed in administrative jobs with a few females employed in underground operations. This is not surprising considering the ECA (2002) indicated that the formal mining sector for example in Zimbabwe and Zambia employs ten per cent $(10 \%)$ women compared with the informal sector which employs up to $50 \%$ women. Basing on the evidence obtained from Marasta MiningLimited the number of women employed is trivial as a result to the nature of mining which is anticipated not to be suitable for women (Pattenden, 1998; Mining Safety, 2013). Hence, women will continue to be passive recipients through their spouses while they engage in activities such as cooking sadzaand kachasu brewing (illicit alcohol), vending, selling grass, farming and also prostitution is actually rife at these areas where small scale mining is prevalent. The latter responsible for HIV/AIDS exacerbated by the presence of gold mining activities and the reckless nature of how the money is spend by makorokoza's. Since mining activities have failed to bring about economic turnaround, jobs and infrastructure, local community members had multiple livelihood strategies that are seasonal and diversified to buffer themselves against unforeseen eventualities and have a reasonable lifestyle such as farming, illegal and formal but casual employment and quarry production has been on the rise (Macdonald, 2012).

\section{Conclusion and Recommendations}

In light of the above raised points, mining projects often result in women facing multiple risks such as loss of agricultural land and property rights, lack of access to resources and heightened insecurity and violence. More so, ASM has heightened socio-economic vulnerability, increased prostitution and greater exposure to sexually transmitted diseases, such as HIV/AIDS on the part of the women who bore the brunt of womanhood.Cultural perceptions on the role of women also play a huge role in promoting or hindering women's involvement and socio-economic development. Thus, understanding the cultural perceptions and attitudes towards women can help mining companies such as Ronghi Xi and Marasta Mining to understand how their presence can create a positive or negative impact on them.

In areas, where women's participation in the formal employment sector is limited and weak, mining companies can create specific policies which can help promote women's employment opportunities and access to resources. There is growing evidence that women and girls often suffer from discrimination and experience significantly more negative consequences as well as lesser benefits from mining as compared to their male counterparts. For instance, women are responsible for a majority of food cultivation and production and play an enormous role in farming. Women often earn a small income by the sale of any surplus agricultural 
products in the local markets thereby sustaining themselves and their families. Men however, hold the formal land title, which gives them greater access to consultation and compensation. Women are often left out of such consultations and important decisions, which can cause a loss of livelihoods, leading to increased insecurity and marginalization. Giving considerations to gender and gender balance are important because it cuts across all aspects of social life and community well-being at large. Mining companies should work to ensure that men and women have equitable access to the benefits of resource development, and that neither are disproportionately placed at risk. This requires a gender sensitive response, and understanding all the gender dimensions at play, including involving women in community-level project consultations, and in national-level policy dialogues on extractive industries. Women must also be involved in education, and in the decisions that affect their lives, and the future of their communities. Gender-sensitive consultation is a means to ensure that policies in the extractive industries meet the needs of women and enhance their well-being. Taking gender bias into account and incorporating ways to address is also central to the development effectiveness and sustainability of mining projects.

\section{References}

Benya, A.P. (2009). Women in mining: A challenge to occupational culture in mines. Unpublished MA dissertation, University of the Witwatersrand, Johannesburg.

Bilton, T., Bonnett, K., Jones, P., Lawson, T., Skinner, D., Stanworth, M., \& Webster, A. (2002). Introductory sociology.(4th edn.). New York: Palgrave Macmillan.

Botha, D. (2013). Women in mining: A conceptual framework for gender issues in the South African mining sector. Unpublished PhD dissertation, North-West University, Potchefstroom. Fourie, J.D. (2009). Managerial challenges faced in a South African platinum mine relating to women employment as required by the Mining Charter. Unpublished MBA minidissertation, North-West University, Potchefstroom.

Grobler, P.A., Wärnich, S., Carrell, M.R., Elbert, N.F., \& Hatfield, R.D. (2011). Human resource management in South Africa.(4th edn.). London: Cengage Learning EMEA.

Hakim, C. (2004). Key issues in women's work: Female diversity and the polarisation of women's employment. (2nd edn.). London: Glasshouse Press.

Haralambos, M., \&Holborn, M. (2008). Sociology: Themes and perspectives. (7th edn.). London: HarperCollins

Keck, J., \& Powel, M. (2006). Women into mining jobs at Inco: Challenging the gender division of labor. In J.J. Gier\& L. Mercier (Eds.), Gender in the development of a global industry, 1670 to the present (pp. 280-295). New York: Palgrave Macmillan.

Kolver, L. (2013). Women still being hassled in male-dominated mining environment.

Lahiri-Dutt, K. (2011). Gendering the field: Towards sustainable livelihoods for mining communities.

Managing Transformation Solutions.(2011). Second Annual Women in Mining Conference.Unpublished report, 23-25 February.

Mcdonald, P. (2012). Workplace sexual harassment 30 years on: A review of the literature.

Mining Safety. (2013). Are we doing enough for the safety of female miners?

Nel, P.S., Kirsten, M., Swanepoel, B.J., Erasmus, B.J., \&Poisat, P. (2012). South African employment relations: Theory and practice. (7th edn.). Pretoria: Van Schaik. 
Nel, P.S., Werner, A., Poisat, P., Sono, T., Du Plessis, A., \&Ngalo, O. (2011). Human resources management.(8th edn.). Cape Town: Oxford University Press Southern Africa.

Noe, R.A., Hollenbeck, J.R., Gerhart, B., \& Wright, P.M. (2008). Human resource management: Gaining a competitive advantage. (8th edn.). New York: McGraw-Hill.

O'Hare, E.A., \&O'Donohue, W. (1998). Sexual harassment: Identifying risk factors. Archives of Sexual Behaviour, 27, 561-580.

Pattenden, C. (1998). Women in mining: A report to the "Women in Mining" Taskforce. The Australasian Institute of Mining and Metallurgy.

Scheepers, A. (2013). Overcoming the challenge of occupational culture at the mines.Unpublished MBA thesis, Stellenbosch University, Stellenbosch.

Slabbert, Y. (1994). Sexual harassment in the workplace.Unpublished master's dissertation, University of Cape Town, Cape Town.

The Guild.(2014). Sexual harassment against women in mines.Unpublished report.

Welman, C., Kruger, F., \& Mitchell, B. (2010). Research methodology.(3rd edn.). Cape Town: Oxford University Press Southern Africa.

Wharton, A.S. (2006). The sociology of gender: An introduction to theory and research. Oxford: Blackwell.

Women in Mining Canada. (2010). Ramp-UP: A study on the status of women in Canada's mining and exploration sector.

Women in Mining South Africa.(2015). WiMSA survey results 2015.Unpublished report.

Zikmund, W.G., Babin, B.J., Carr, J.C., \& Griffin, M. (2010). Business research methods.(8th edn.). Australia: South-Western Cengage Learning. 